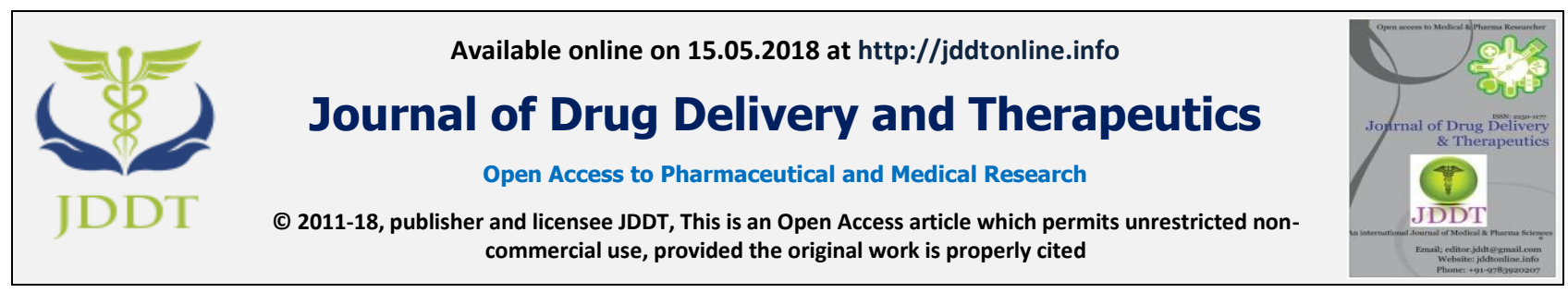

Open

\title{
DFT study including NBO, NLO response and reactivity descriptor of bis and tris (1, 3-dithiole) tetrathiafulvalene
}

\author{
Tahar Abbaz $^{1^{*}}$, Amel Bendjeddou ${ }^{1}$ and Didier Villemin ${ }^{2}$ \\ ${ }^{1}$ Laboratory of Aquatic and Terrestrial Ecosystems, Org. and Bioorg. Chem. Group, University of Mohamed-Cherif Messaadia, \\ Souk Ahras, 41000, Algeria \\ ${ }^{2}$ Laboratory of Molecular and Thio-Organic Chemistry, UMR CNRS 6507, INC3M, FR 3038, Labex EMC3, ensicaen \& University \\ of Caen, Caen 14050, France
}

\section{ABSTRACT}

We present a density functional theory (DFT) study on the reactivity of bis and tris (1,3-dithiole) TTF 1-4 by using B3LYP/6-31G $(\mathrm{d}, \mathrm{p})$ level. The possible electrophile and nucleophile attacking sites of the title compounds is identified using MEP surface plot study. Highest occupied molecular orbital (HOMO) and lowest unoccupied molecular orbital (LUMO) energy gaps were calculated to explain the frontier molecular orbitals and to predict the quantum chemical descriptors. Local reactivity properties have been investigated using average local ionization energies and Fukui functions. Natural Bond Orbital analysis was computed and possible transitions were correlated with the electronic transitions. The calculated first hyperpolarizability $\left(\beta_{0}\right)$ of bis and tris $(1,3$-dithiole) TTF molecules, indicates that investigated molecules might have not the NLO applications.

Keywords: Tetrathiafulvalenes; density functional theory; computational chemistry; quantum chemical calculations.

Article Info: Received 10 Feb, 2018; Review Completed 02 May 2018; Accepted 07 May 2018; Available online 15 May 2018

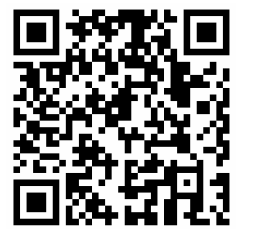

Cite this article as:

Abbaz T, Bendjeddou A, Villemin D, DFT study including NBO, NLO response and reactivity descriptor of bis and tris (1,3-dithiole) tetrathiafulvalene, Journal of Drug Delivery and Therapeutics. 2018; 8(3):96-105 DOI: http://dx.doi.org/10.22270/jddt.v8i3.1716

Tahar Abbaz, Laboratory of Aquatic and Terrestrial Ecosystems, Org. and Bioorg. Chem. Group, University of Mohamed-Cherif Messaadia, Souk Ahras, 41000, Algeria

\section{INTRODUCTION}

The tetrathiafulvalene (TTF) derivatives are one kind of organic semiconductors that have been paid considerable attention as potential charge transfer materials in organic electronic devices in recent years ${ }^{1-5}$. They have been widely explored in both materials and supramolecular chemistry $^{6}$. The $\pi$-electron donor tetrathiafulvalene (TTF) and its derivatives have been studied extensively for their use in a variety of applications such as organic metals and superconductors ${ }^{7}$, Langmuir-Blodgett films ${ }^{8}$, molecular sensors ${ }^{9}$, non-linear optics ${ }^{10}$, field effect transistors ${ }^{11}$ and photovoltaics ${ }^{10}$.

Density functional theory based on the Becke's three parameter hybrid exchange functional combined with the Lee e Yang e Parr non-local correlation function level of theory displays good achievement on the characterization of the organic molecules ${ }^{12-14}$ as a consequence of the recovering of the electron correlation in the self-consistent Kohn e Sham procedure throughout the electron density functions ${ }^{15-17}$.

The present research work predominantly focused on the computational study of bis and tris (1,3-dithiole) TTF 14 reported in literature ${ }^{18}$ by DFT/B3LYP method within 6-31G (d,p) basis set. The optimized structural parameters such as bond lengths, bond angles and dihedral angles have been computed using the same method cited above. The global reactivity descriptors, namely, hardness $(\eta)$, chemical potential $(\mu)$ and electrophilicity index $(\omega)$ are also calculated to understand the reactive nature of the investigated compounds. Fukui functions are determined to predict the reactive sites in these molecules. In addition the 
molecular electrostatic potential, the frontier molecular orbital, the intramolecular charge transfer and non-linear optical activity of the title compounds have been also studied clearly.

\section{MATERIALS AND METHODS}

The theoretical calculations were performed using the Gaussian 09W program package ${ }^{19}$ and B3LYP (Becke's Three parameter Hybrid Functional Using the LYP Correlation Functional) approach in conjunction with the 6-31G (d,p) basis set.

\section{RESULTS AND DISCUSSION}

\subsection{Molecular Geometry}

The optimized structural parameters such as bond lengths, bond angles and dihedral angles of bis and tris (1,3-dithiole) TTF $\mathbf{1 - 4}$ are determined by theoretical B3LYP method with 6-31G (d,p) basis set and presented in Tables 1-4 in accordance with the atom numbering scheme as given in Figure 1.

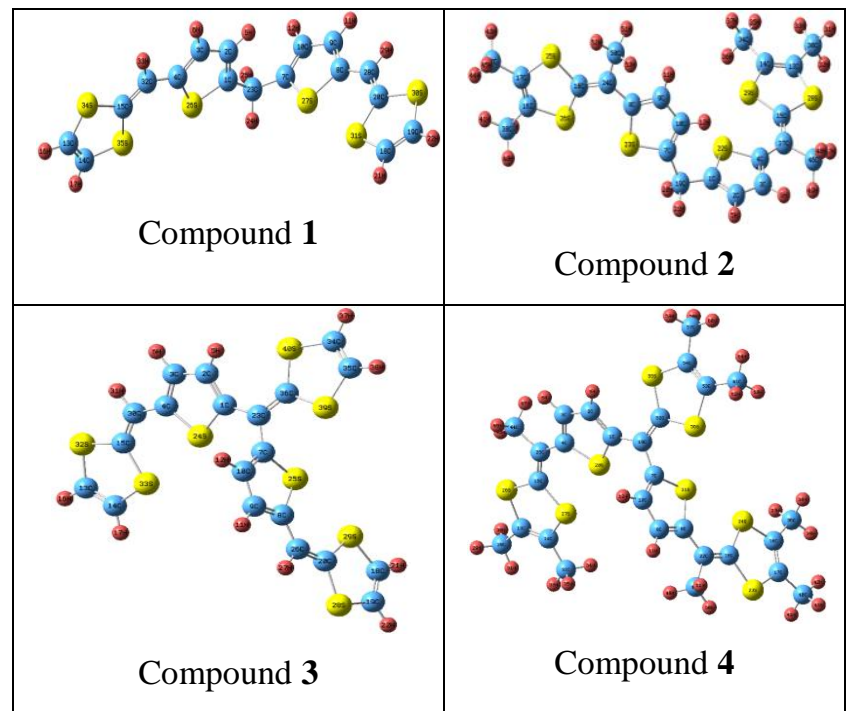

Figure 1: Optimized molecular structure of bis and tris (1,3-dithiole) TTF 1-4

Table 1: Optimized geometric parameters of compound 1

\begin{tabular}{lrlrlr}
\hline \multicolumn{2}{c}{ Bond Length $(\mathbf{\AA})$} & \multicolumn{2}{c}{ Bond Angles $\left(^{\circ}\right)$} & \multicolumn{2}{c}{ Dihedral Angles $\left(^{\circ}\right)$} \\
\hline $\mathrm{R}(1,2)$ & 1.370 & $\mathrm{~A}(2,1,23)$ & 129.406 & $\mathrm{D}(23,1,2,3)$ & 177.320 \\
$\mathrm{R}(1,23)$ & 1.512 & $\mathrm{~A}(2,1,26)$ & 110.547 & $\mathrm{D}(26,1,2,5)$ & 179.740 \\
$\mathrm{R}(1,26)$ & 1.749 & $\mathrm{~A}(23,1,26)$ & 119.993 & $\mathrm{D}(2,1,23,7)$ & 23.443 \\
$\mathrm{R}(2,3)$ & 1.419 & $\mathrm{~A}(1,2,3)$ & 113.604 & $\mathrm{D}(2,1,23,24)$ & 147.495 \\
$\mathrm{R}(2,5)$ & 1.083 & $\mathrm{~A}(1,2,5)$ & 122.485 & $\mathrm{D}(26,1,23,25)$ & 79.958 \\
$\mathrm{R}(4,32)$ & 1.440 & $\mathrm{~A}(3,4,32)$ & 125.136 & $\mathrm{D}(2,3,4,32)$ & 179.771 \\
$\mathrm{R}(8,28)$ & 1.441 & $\mathrm{~A}(10,7,23)$ & 128.063 & $\mathrm{D}(26,4,32,33)$ & 179.630 \\
$\mathrm{R}(13,14)$ & 1.337 & $\mathrm{~A}(27,8,28)$ & 125.444 & $\mathrm{D}(10,7,23,24)$ & 128.525 \\
$\mathrm{R}(13,16)$ & 1.083 & $\mathrm{~A}(7,10,12)$ & 122.462 & $\mathrm{D}(10,7,23,25)$ & 14.070 \\
$\mathrm{R}(13,34)$ & 1.756 & $\mathrm{~A}(14,13,34)$ & 117.694 & $\mathrm{D}(27,7,23,1)$ & 72.330 \\
$\mathrm{R}(15,32)$ & 1.355 & $\mathrm{~A}(16,13,34)$ & 117.401 & $\mathrm{D}(27,8,9,11)$ & 179.991 \\
$\mathrm{R}(15,34)$ & 1.789 & $\mathrm{~A}(34,15,35)$ & 112.921 & $\mathrm{D}(9,8,28,20)$ & 179.803 \\
$\mathrm{R}(18,21)$ & 1.083 & $\mathrm{~A}(21,18,31)$ & 117.059 & $\mathrm{D}(34,13,14,17)$ & 179.950 \\
$\mathrm{R}(18,31)$ & 1.761 & $\mathrm{~A}(4,32,15)$ & 130.874 & $\mathrm{D}(32,15,34,13)$ & 179.722 \\
$\mathrm{R}(32,33)$ & 1.088 & $\mathrm{~A}(13,34,15)$ & 95.816 & $\mathrm{D}(30,20,28,8)$ & 179.945 \\
\hline
\end{tabular}

Table 2: Optimized geometric parameters of compound 2

\begin{tabular}{lrlllr}
\hline \multicolumn{2}{c}{ Bond Length $(\AA)$} & \multicolumn{2}{c}{ Bond Angles $\left(^{\circ}\right)$} & \multicolumn{2}{c}{ Dihedral Angles $\left(^{\circ}\right)$} \\
\hline $\mathrm{R}(1,2)$ & 1.369 & $\mathrm{~A}(2,1,19)$ & 128.179 & $\mathrm{D}(19,1,2,3)$ & 179.886 \\
$\mathrm{R}(1,19)$ & 1.503 & $\mathrm{~A}(2,1,22)$ & 110.304 & $\mathrm{D}(22,1,19,20)$ & 50.080 \\
$\mathrm{R}(1,22)$ & 1.746 & $\mathrm{~A}(19,1,22)$ & 121.516 & $\mathrm{D}(22,1,19,21)$ & 164.577 \\
$\mathrm{R}(2,3)$ & 1.419 & $\mathrm{~A}(1,2,3)$ & 113.869 & $\mathrm{D}(1,2,3,6)$ & 179.581 \\
$\mathrm{R}(2,5)$ & 1.085 & $\mathrm{~A}(1,2,5)$ & 122.604 & $\mathrm{D}(3,4,27,46)$ & 4.751 \\
$\mathrm{R}(3,4)$ & 1.385 & $\mathrm{~A}(3,4,27)$ & 125.713 & $\mathrm{D}(22,4,27,15)$ & 6.453 \\
$\mathrm{R}(3,6)$ & 1.082 & $\mathrm{~A}(10,7,23)$ & 110.430 & $\mathrm{D}(10,7,19,21)$ & 96.551 \\
$\mathrm{R}(4,27)$ & 1.457 & $\mathrm{~A}(8,9,11)$ & 122.827 & $\mathrm{D}(23,7,19,1)$ & 159.052 \\
$\mathrm{R}(13,14)$ & 1.344 & $\mathrm{~A}(14,13,28)$ & 116.772 & $\mathrm{D}(23,7,19,20)$ & 34.986 \\
$\mathrm{R}(13,28)$ & 1.773 & $\mathrm{~A}(14,13,30)$ & 128.006 & $\mathrm{D}(19,7,23,8)$ & 177.556 \\
$\mathrm{R}(13,30)$ & 1.503 & $\mathrm{~A}(17,16,38)$ & 128.105 & $\mathrm{D}(24,8,9,10)$ & 179.753 \\
$\mathrm{R}(15,27)$ & 1.364 & $\mathrm{~A}(1,19,20)$ & 110.142 & $\mathrm{D}(9,8,24,18)$ & 171.027 \\
$\mathrm{R}(15,28)$ & 1.787 & $\mathrm{~A}(4,27,15)$ & 126.311 & $\mathrm{D}(23,8,24,50)$ & 172.444 \\
$\mathrm{R}(19,20)$ & 1.097 & $\mathrm{~A}(4,27,46)$ & 114.418 & $\mathrm{D}(8,9,10,12)$ & 179.526 \\
$\mathrm{R}(27,46)$ & 1.517 & $\mathrm{~A}(15,27,46)$ & 119.258 & $\mathrm{D}(14,13,30,31)$ & 121.645 \\
\hline
\end{tabular}


Table 3: Optimized geometric parameters of compound 3

\begin{tabular}{lrlrll}
\hline \multicolumn{2}{l}{ Bond Length $(\stackrel{\AA}{\mathbf{A}})$} & \multicolumn{2}{c}{ Bond Angles $\left.\mathbf{(}^{\circ}\right)$} & \multicolumn{2}{c}{ Dihedral Angles $\left(^{\circ}\right)$} \\
\hline $\mathrm{R}(1,2)$ & 1.385 & $\mathrm{~A}(2,1,23)$ & 131.383 & $\mathrm{D}(32,15,30,4)$ & 179.947 \\
$\mathrm{R}(1,23)$ & 1.457 & $\mathrm{~A}(2,1,24)$ & 109.638 & $\mathrm{D}(21,18,29,20)$ & 179.903 \\
$\mathrm{R}(1,24)$ & 1.763 & $\mathrm{~A}(23,1,24)$ & 118.977 & $\mathrm{D}(32,13,14,17)$ & 179.841 \\
$\mathrm{R}(2,3)$ & 1.410 & $\mathrm{~A}(1,2,3)$ & 113.932 & $\mathrm{D}(33,15,30,31)$ & 179.820 \\
$\mathrm{R}(2,5)$ & 1.082 & $\mathrm{~A}(1,2,5)$ & 123.377 & $\mathrm{D}(2,3,4,30)$ & 179.604 \\
$\mathrm{R}(3,4)$ & 1.385 & $\mathrm{~A}(3,2,5)$ & 122.616 & $\mathrm{D}(11,9,10,7)$ & 179.533 \\
$\mathrm{R}(4,30)$ & 1.438 & $\mathrm{~A}(3,4,30)$ & 124.796 & $\mathrm{D}(37,34,35,39)$ & 179.414 \\
$\mathrm{R}(13,14)$ & 1.337 & $\mathrm{~A}(14,13,16)$ & 124.948 & $\mathrm{D}(23,1,2,3)$ & 179.252 \\
$\mathrm{R}(13,16)$ & 1.083 & $\mathrm{~A}(14,13,32)$ & 117.622 & $\mathrm{D}(30,15,32,13)$ & 178.743 \\
$\mathrm{R}(13,32)$ & 1.756 & $\mathrm{~A}(1,23,7)$ & 117.676 & $\mathrm{D}(23,7,10,9)$ & 178.631 \\
$\mathrm{R}(15,30)$ & 1.357 & $\mathrm{~A}(1,23,36)$ & 124.336 & $\mathrm{D}(23,36,39,35)$ & 176.280 \\
$\mathrm{R}(15,32)$ & 1.788 & $\mathrm{~A}(7,23,36)$ & 117.987 & $\mathrm{D}(1,23,36,39)$ & 174.988 \\
$\mathrm{R}(20,26)$ & 1.356 & $\mathrm{~A}(4,30,15)$ & 130.782 & $\mathrm{D}(24,1,23,36)$ & 159.435 \\
$\mathrm{R}(23,36)$ & 1.369 & $\mathrm{~A}(13,32,15)$ & 95.810 & $\mathrm{D}(10,7,23,36)$ & 103.254 \\
$\mathrm{R}(30,31)$ & 1.088 & $\mathrm{~A}(25,8,26)$ & 125.557 & $\mathrm{D}(25,7,23,1)$ & 101.121 \\
\hline
\end{tabular}

Table 4: Optimized geometric parameters of compound 4

\begin{tabular}{lrlrlr}
\hline \multicolumn{2}{l}{ Bond Length $(\stackrel{\bullet}{ } \mathbf{A})$} & \multicolumn{2}{c}{ Bond Angles $\left(^{\circ}\right)$} & \multicolumn{2}{c}{ Dihedral Angles $\left(^{\circ}\right)$} \\
\hline $\mathrm{R}(1,2)$ & 1.383 & $\mathrm{~A}(2,1,19)$ & 131.255 & $\mathrm{D}(22,8,9,10)$ & 179.996 \\
$\mathrm{R}(1,19)$ & 1.458 & $\mathrm{~A}(2,1,20)$ & 109.539 & $\mathrm{D}(36,16,24,18)$ & 178.514 \\
$\mathrm{R}(1,20)$ & 1.760 & $\mathrm{~A}(19,1,20)$ & 119.202 & $\mathrm{D}(26,15,25,4)$ & 177.710 \\
$\mathrm{R}(2,3)$ & 1.412 & $\mathrm{~A}(1,2,3)$ & 113.981 & $\mathrm{D}(20,1,2,5)$ & 176.619 \\
$\mathrm{R}(4,25)$ & 1.455 & $\mathrm{~A}(1,2,5)$ & 123.372 & $\mathrm{D}(8,22,48,50)$ & 173.146 \\
$\mathrm{R}(7,19)$ & 1.484 & $\mathrm{~A}(3,4,20)$ & 108.950 & $\mathrm{D}(4,25,44,45)$ & 165.085 \\
$\mathrm{R}(13,14)$ & 1.344 & $\mathrm{~A}(3,4,25)$ & 125.587 & $\mathrm{D}(20,1,19,52)$ & 157.119 \\
$\mathrm{R}(13,26)$ & 1.773 & $\mathrm{~A}(14,13,26)$ & 116.719 & $\mathrm{D}(14,13,28,29)$ & 122.273 \\
$\mathrm{R}(13,28)$ & 1.503 & $\mathrm{~A}(14,13,28)$ & 128.005 & $\mathrm{D}(17,16,36,37)$ & 119.322 \\
$\mathrm{R}(15,25)$ & 1.365 & $\mathrm{~A}(26,13,28)$ & 115.273 & $\mathrm{D}(13,14,32,34)$ & 118.285 \\
$\mathrm{R}(15,26)$ & 1.786 & $\mathrm{~A}(1,19,7)$ & 117.679 & $\mathrm{D}(18,22,48,51)$ & 113.118 \\
$\mathrm{R}(19,52)$ & 1.369 & $\mathrm{~A}(1,19,52)$ & 124.006 & $\mathrm{D}(15,25,44,46)$ & 104.471 \\
$\mathrm{R}(25,44)$ & 1.518 & $\mathrm{~A}(7,19,52)$ & 118.312 & $\mathrm{D}(21,7,19,1)$ & 102.748 \\
$\mathrm{R}(44,46)$ & 1.097 & $\mathrm{~A}(13,26,15)$ & 97.280 & $\mathrm{D}(56,53,61,63)$ & 62.465 \\
$\mathrm{R}(1,2)$ & 1.383 & $\mathrm{~A}(25,15,26)$ & 122.080 & $\mathrm{D}(24,16,36,38)$ & 58.651 \\
\hline & \multicolumn{5}{c}{}
\end{tabular}

\subsection{Molecular Electrostatic Potential (MEP)}

The MEP is a very useful feature to study reactivity given that an approaching electrophile will be attracted to negative regions (the electron distribution in where effect is dominant). In the majority of the MEPs, while the maximum negative region which preferred site for electrophilic attack indications as red color, the maximum positive region which preferred site for nucleophilic attack symptoms as blue color. The importance of MEP lies in the fact that it simultaneously displays molecular size, shape as well as positive, negative and neutral electrostatic potential (MEP) of bis and tris (1,3-dithiole) TTF $\mathbf{1 - 4}$ is calculated by B3LYP/6-31G (d,p) and shown in Figure 2. The MEP is a plot of electrostatic potential mapped onto the constant electron density surface. The different values of the electrostatic potential at the surface are represented by different colors. Potential increases in the order red < orange $<$ yellow $<$ green $<$ blue.

As observed from the figure $\mathbf{2}$ that, in all molecules, the regions exhibiting the negative electrostatic potential are localized near the thiophene spacer units while the regions presenting the positive potential are localized vicinity of the hydrogen atoms and alkyl groups.

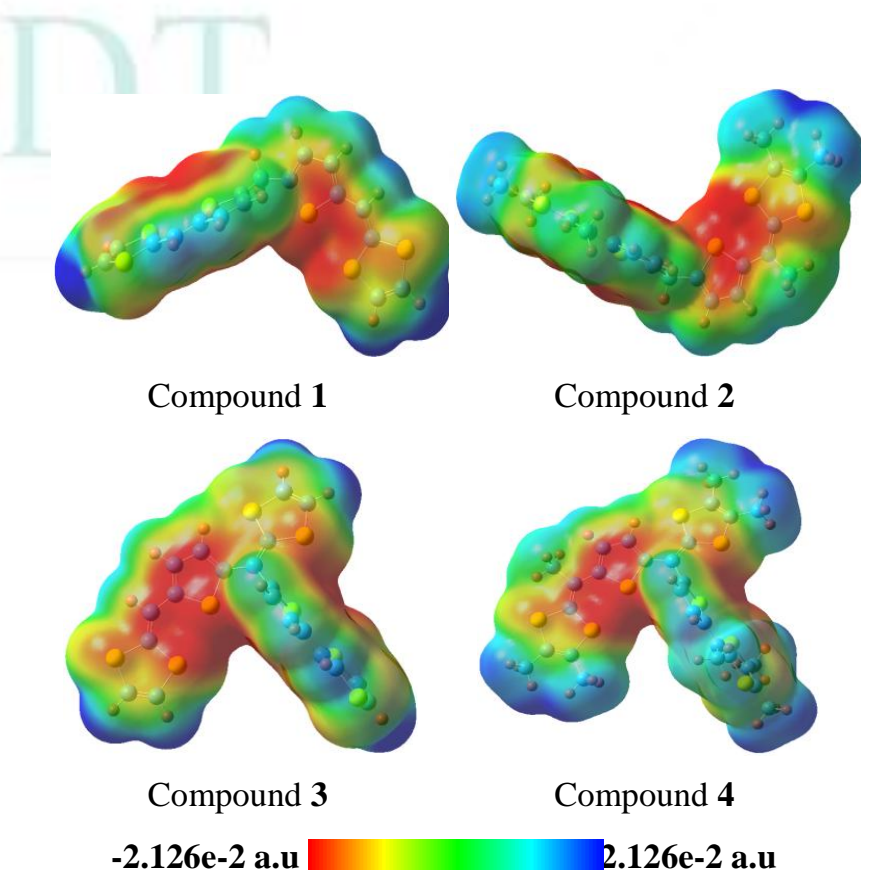

Figure 2: Molecular electrostatic potential surface of bis and tris (1, 3-dithiole) TTF 1-4 


\subsection{Frontier Molecular Orbitals (FMOs)}

The properties of the frontier molecular orbitals (FMOs) like energy are very applied for physicists and chemists. The electron densities of these FMOs were used for predicting the most reactive position in $\pi$-electron systems and also explained several types of reaction in conjugated system $^{20}$. Moreover, eigen values of the lowest unoccupied molecular orbital (LUMO) and the highest occupied molecular orbital (HOMO) and their energy gap reflect the chemical reactivity of the molecule. Recently the energy gap between HOMO and LUMO has been used to prove the bioactivity from intramolecular charge transfer (ICT) ${ }^{21,22}$. The HOMOLUMO energy gap for the studied compounds were calculated by B3LYP/6-31G (d,p) method. The HOMO1, HOMO, LUMO and LUMO+1 picture of compound 3 with a small energy gap is shown in Figure 3.

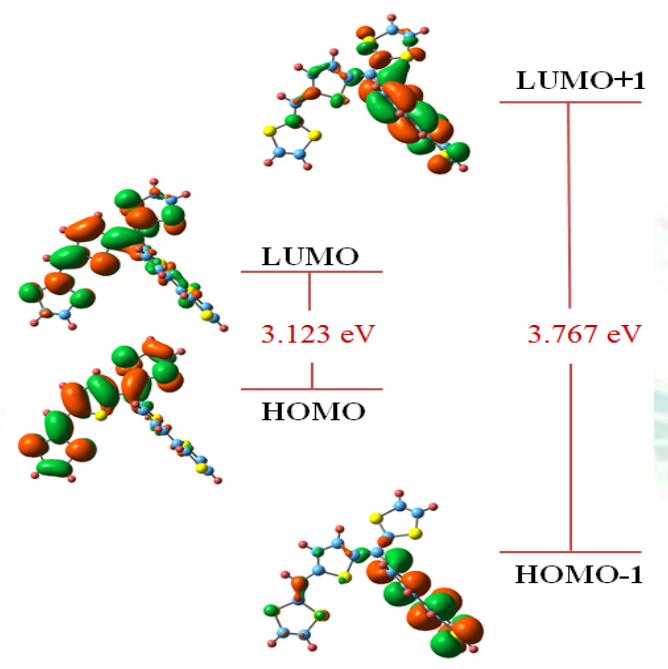

Figure 3: HOMO-LUMO Structure with the energy level diagram of compound $\mathbf{3}$

\subsection{Global Reactivity Descriptors}

Based on the energies of the frontier molecular orbitals, various chemical reactivity descriptors such as electronegativity $(\chi)$, chemical potential $(\mu)$, chemical hardness $(\eta)$ global softness $(S)$ and global electrophilicity index $(\omega)^{23-27}$ were proposed for understanding the different pharmacological aspects of drug molecules. These descriptors are calculated using equations given below:

$$
\begin{gathered}
\chi=\frac{(I+A)}{2} \\
\mu=-\chi=-\frac{(I+A)}{2} \\
\eta=\frac{(I-A)}{2} \\
S=\frac{1}{2 \eta} \\
\omega=\frac{\mu^{2}}{2 \eta}
\end{gathered}
$$

The chemical hardness is a measure of the resistance to charge transference ${ }^{28}$, while the electronegativity is a measure of the tendency to attract electrons in a chemical bond, as is defined as the negative of the chemical potential in $\mathrm{DFT}^{28}$. The electrophilicity index $(\omega)$ contains information about both electron transfer (chemical potential) and stability (hardness) and is a better descriptor of global chemical reactivity. For the studied compounds, the chemical reactivity descriptors are computed by B3LYP/6-31G (d,p) method and given in Table 5.

Table 5: Quantum chemical descriptors of bis and tris (1,3-dithiole) TTF 1-4

\begin{tabular}{rrrrr}
\hline Parameters & Compound 1 & Compound 2 & Compound 3 & Compound 4 \\
\hline $\mathbf{E}_{\text {HOMO }}(\mathbf{e V})$ & -4.699 & -4.531 & -4.349 & -4.165 \\
$\mathbf{E}_{\mathbf{L U M O}}(\mathbf{e V})$ & -0.988 & -0.771 & -1.226 & -0.983 \\
$\boldsymbol{\Delta} \mathbf{E}_{\mathbf{g a p}}(\mathbf{e V})$ & 3.711 & 3.759 & 3.123 & 3.182 \\
$\mathbf{I E}(\mathbf{e V})$ & 4.699 & 4.531 & 4.349 & 4.165 \\
$\mathbf{A}(\mathbf{e V})$ & 0.988 & 0.711 & 1.226 & 0.983 \\
$\boldsymbol{\mu}(\mathbf{e V})$ & -2.844 & -2.651 & -2.787 & -2.574 \\
$\boldsymbol{\chi}(\mathbf{e V})$ & 2.844 & 2.651 & 2.787 & 2.574 \\
$\mathbf{\eta}(\mathbf{e V})$ & 1.855 & 1.880 & 1.561 & 1.591 \\
$\mathbf{S}(\mathbf{e V})$ & 0.269 & 0.266 & 0.320 & 0.314 \\
$\mathbf{\omega}(\mathbf{e V})$ & 2.179 & 1.870 & 2.488 & 2.082 \\
\hline
\end{tabular}

The compound which have the lowest energetic gap is the compound $3\left(\Delta \mathrm{E}_{\text {gap }}=3.123 \mathrm{eV}\right)$. This lower gap allows it to be the softest molecule. The compound that has the highest energy gap is the compound $2\left(\Delta \mathrm{E}_{\text {gap }}=\right.$ $3.759 \mathrm{eV})$. The compound that has the highest HOMO energy is the compound $4\left(\mathrm{E}_{\mathrm{HOMO}}=-4.165 \mathrm{eV}\right)$. This higher energy allows it to be the best electron donor. The compound that has the lowest LUMO energy is the compound $3\left(\mathrm{E}_{\mathrm{LUMO}}=-1.226 \mathrm{eV}\right)$ which signifies that it can be the best electron acceptor. The two properties like $I$ (potential ionization) and $A$ (affinity) are so important, the determination of these two properties allow us to calculate the absolute electronegativity $(\chi)$ and the absolute hardness $(\eta)$. These two parameters are related to the one-electron orbital energies of the HOMO and LUMO respectively. Compound $\mathbf{4}$ has lowest value of the potential ionization $(I=4.165 \mathrm{eV})$, so that will be the better electron donor. Compound $\mathbf{3}$ has the largest value of the affinity $(A=1.226 \mathrm{eV})$, so it is the better electron acceptor. The chemical reactivity varies with the structural of molecules. Chemical hardness (softness) value of compound $\mathbf{3}(\eta=1.561 \mathrm{eV}, \mathbf{S}=$ 
$0.320 \mathrm{eV}$ ) is lesser (greater) among all the molecules. Thus, compound $\mathbf{3}$ is found to be more reactive than all the compounds. Compound $\mathbf{1}$ possesses higher electronegativity value $(\chi=2.844 \mathrm{eV})$ than all compounds so; it is the best electron acceptor. The value of $\omega$ for compound $3(\omega=2.488 \mathrm{eV})$ indicates that it is the stronger electrophiles than all compounds. Compound $\mathbf{3}$ has the smaller frontier orbital gap so, it is more polarizable and is associated with a high chemical reactivity, low kinetic stability and is also termed as soft molecule.

\subsection{Local Reactivity Descriptors}

Parr and Yang $^{29}$ have demonstrated that most of the frontier-electron density theory of chemical reactivity can be rationalized from the DFT. Parr and Yang defined a Fukui function $\left(f_{\mathrm{k}}\right)$ to describe electrophilic attack $\left(f_{\mathrm{k}}^{-}\right)$, nucleophilic attack $\left(f_{\mathrm{k}}^{+}\right)$and neutral (radical) attack $\left(f_{\mathrm{k}}{ }^{0}\right)$. Yang and Mortier proposed a finite difference approach to calculate Fukui function indices $^{30}$. In a finite difference approximation, the condensed Fukui function values are given Yang et al. as

$$
\begin{aligned}
& f_{j}^{-}=q_{j}(N)-q_{j}(N-1) \text { for nucleophilic attack } \\
& f_{j}^{+}=q_{j}(N+1)-q_{j}(N) \text { for electrophilic attack } \\
& f_{j}^{0}=\frac{1}{2}\left[q_{j}(N+1)-q_{j}(N-1)\right] \text { for radical attack }
\end{aligned}
$$

where $q_{\mathrm{k}}$ is the gross charge of the kth atom in the neutral $(\mathrm{N})$, anionic $(\mathrm{N}+1)$ and cationic $(\mathrm{N}-1)$ molecule, respectively, all with the ground state geometry of the $\mathrm{N}$ electron molecule. Gross charges may be determined by Mulliken, Hirschfeld and Natural charge analysis. The reactive sites on bis and tris (1,3-dithiole) TTF 1-4 are calculated by the DFT/B3LYP method with 6-31G (d,p) basis set and shown in Tables 6-7.

Table 6: Order of the reactive sites on compounds $\mathbf{1}$ and 2

\begin{tabular}{lccccccccc}
\hline \multicolumn{4}{c}{ Compound 1 } & \multicolumn{5}{c}{ Compound 2 } \\
\hline Atom & $4 \mathrm{C}$ & $8 \mathrm{C}$ & $1 \mathrm{C}$ & $15 \mathrm{C}$ & Atom & $8 \mathrm{C}$ & $4 \mathrm{C}$ & $14 \mathrm{C}$ & $16 \mathrm{C}$ \\
$\boldsymbol{f}^{+}$ & 0.043 & 0.042 & 0.008 & 0.004 & $\boldsymbol{f}^{+}$ & 0.030 & 0.025 & 0.001 & 0.001 \\
Atom & $28 \mathrm{C}$ & $32 \mathrm{C}$ & $7 \mathrm{C}$ & $27 \mathrm{~S}$ & Atom & $24 \mathrm{C}$ & $27 \mathrm{C}$ & $1 \mathrm{C}$ & $17 \mathrm{C}$ \\
$\boldsymbol{f}^{-}$ & 0.010 & 0.009 & 0.003 & 0.002 & $\boldsymbol{f}^{-}$ & 0.036 & 0.033 & 0.018 & 0.010 \\
Attom & $4 \mathrm{C}$ & $8 \mathrm{C}$ & $7 \mathrm{C}$ & $1 \mathrm{C}$ & Atom & $17 \mathrm{C}$ & $13 \mathrm{C}$ & $16 \mathrm{C}$ & $14 \mathrm{C}$ \\
$\boldsymbol{f}^{\boldsymbol{0}}$ & 0.002 & 0.003 & 0.008 & 0.008 & $\boldsymbol{f}^{\boldsymbol{0}}$ & 0.002 & 0.002 & 0.001 & 0.001 \\
\hline
\end{tabular}

Table 7: Order of the reactive sites on compounds 3 and 4

\begin{tabular}{cccccccccc}
\hline \multicolumn{1}{c}{ Compound 3 } & \multicolumn{5}{c}{ Compound 4 } \\
\hline Atom & $36 \mathrm{C}$ & $1 \mathrm{C}$ & $8 \mathrm{C}$ & $10 \mathrm{C}$ & Atom & $52 \mathrm{C}$ & $1 \mathrm{C}$ & $10 \mathrm{C}$ & $8 \mathrm{C}$ \\
$\boldsymbol{f}^{+}$ & 0.097 & 0.057 & 0.046 & 0.036 & $\boldsymbol{f}^{+}$ & 0.094 & 0.045 & 0.035 & 0.031 \\
Atom & $23 \mathrm{C}$ & $7 \mathrm{C}$ & $26 \mathrm{C}$ & $30 \mathrm{C}$ & Atom & $19 \mathrm{C}$ & $7 \mathrm{C}$ & $22 \mathrm{C}$ & $25 \mathrm{C}$ \\
$\boldsymbol{f}^{-}$ & 0.178 & 0.065 & 0.031 & 0.013 & $\boldsymbol{f}^{-}$ & 0.177 & 0.070 & 0.036 & 0.034 \\
Atom & $7 \mathrm{C}$ & $4 \mathrm{C}$ & $23 \mathrm{C}$ & $8 \mathrm{C}$ & Atom & $7 \mathrm{C}$ & $53 \mathrm{C}$ & $13 \mathrm{C}$ & $22 \mathrm{C}$ \\
$\boldsymbol{f}^{\boldsymbol{0}}$ & 0.010 & 0.010 & 0.008 & 0.005 & $\boldsymbol{f}^{\boldsymbol{0}}$ & 0.008 & 0.004 & 0.002 & 0.002 \\
\hline
\end{tabular}

The parameters of local reactivity descriptors show that $4 \mathrm{C}, 8 \mathrm{C}, 36 \mathrm{C}$ and $52 \mathrm{C}$ are the more reactive sites in compounds 1, 2, 3 and 4 respectively for nucleophilic attacks. The more reactive sites for electrophilic attacks are 28C, 24C, 23C and 19C for compounds 1, 2, 3 and 4 respectively. The more reactive sites in radical attacks are $4 \mathrm{C}, 17 \mathrm{C}$, for compounds $\mathbf{1}, \mathbf{2}$ respectively and $7 \mathrm{C}$ for the both compounds 3 and 4 .

\subsection{Natural Bond Orbital Analysis (NBO)}

A useful aspect of the NBO method is that it gives information about intra and intermolecular bonding and interactions among bonds and also provides a convenient basis for investigating the interactions in both filled and virtual orbital spaces along with charge transfer and conjugative interactions in molecular system. Some electron donor orbital, acceptor orbital and the interacting stabilization energies resulting from the second-order micro-disturbance theory are reported $^{31,32}$.The large value of second order stabilization energy $\left(\mathrm{E}^{(2)}\right)$ shows that the more donating tendency from electron donors to electron acceptors and the greater the extent of conjugation of the whole system $^{33}$. In order to characterize the intra and intermolecular interactions quantitatively, a secondorder perturbation theory is applied that gives the energy lowering associated with such interactions. For each donor $\mathrm{NBO}(\mathrm{i})$ and acceptor $\mathrm{NBO}(\mathrm{j})$, stabilization energy $\left(\mathrm{E}^{(2)}\right)$ associated with electron delocalization between donor and acceptor is estimated by an equation as ${ }^{34,35}$.

$$
E^{(2)}=-q_{i} \frac{\left(F_{i j}\right)^{2}}{\varepsilon_{i}-\varepsilon_{j}}
$$

where $\mathrm{q}_{\mathrm{i}}$ is the donor orbital occupancy; $\varepsilon_{\mathrm{i}}, \varepsilon_{\mathrm{j}}$ are orbital energies of donor and acceptor NBO orbitals, respectively; $F_{i j}$ is the off-diagonal Fock or Kohn-Sham matrix element. The results of second-order perturbation theory analysis of the Fock Matrix of bis and tris (1,3dithiole) TTF 1-4 at B3LYP/6-31G (d,p) level of theory are presented in Tables 8-11. 
Table 8: Second order perturbation theory analysis of Fock matrix on NBO of compound 1

\begin{tabular}{|c|c|c|c|c|c|c|}
\hline Donor(i) & ED/e & Acceptor(j) & ED/e & $\begin{array}{c}\mathrm{E}(2) \\
\text { Kcal/mol }\end{array}$ & $\begin{array}{c}\mathbf{E}(\mathbf{j})-\mathbf{E}(\mathbf{i}) \\
\text { a.u }\end{array}$ & $\begin{array}{c}\text { F(i.j) } \\
\text { a.u }\end{array}$ \\
\hline LP(2) S34 & 1.76226 & $\pi^{*}(\mathrm{C} 13-\mathrm{C} 14)$ & 0.22006 & 22.85 & 0.25 & 0.068 \\
\hline LP(2) S30 & 1.76003 & $\pi *(\mathrm{C} 18-\mathrm{C} 19)$ & 0.21963 & 22.77 & 0.25 & 0.068 \\
\hline LP(2) S35 & 1.75627 & $\pi^{*}(\mathrm{C} 13-\mathrm{C} 14)$ & 0.22006 & 22.21 & 0.25 & 0.067 \\
\hline LP(2) S31 & 1.75279 & $\pi *(\mathrm{C} 18-\mathrm{C} 19)$ & 0.21963 & 22.20 & 0.25 & 0.067 \\
\hline LP(2) S27 & 1.66431 & $\pi *(\mathrm{C} 7-\mathrm{C} 10)$ & 0.31685 & 21.18 & 0.27 & 0.068 \\
\hline LP(2) S26 & 1.67209 & $\pi^{*}(\mathrm{C} 1-\mathrm{C} 2)$ & 0.31139 & 20.95 & 0.28 & 0.068 \\
\hline $\mathrm{LP}(2) \mathrm{S} 27$ & 1.66431 & $\pi^{*}(\mathrm{C} 8-\mathrm{C} 9)$ & 0.36906 & 20.87 & 0.27 & 0.067 \\
\hline LP(2) S26 & 1.67209 & $\pi *(\mathrm{C} 3-\mathrm{C} 4)$ & 0.36665 & 20.18 & 0.27 & 0.067 \\
\hline $\mathrm{LP}(2) \mathrm{S} 31$ & 1.75279 & $\pi *(\mathrm{C} 20-\mathrm{C} 28)$ & 0.32339 & 20.11 & 0.27 & 0.067 \\
\hline LP(2) S35 & 1.75627 & $\pi *(\mathrm{C} 15-\mathrm{C} 32)$ & 0.32218 & 19.80 & 0.27 & 0.067 \\
\hline$\pi(\mathrm{C} 3-\mathrm{C} 4)$ & 1.80546 & $\pi^{*}(\mathrm{C} 15-\mathrm{C} 32)$ & 0.32218 & 19.23 & 0.27 & 0.067 \\
\hline$\pi(\mathrm{C} 8-\mathrm{C} 9)$ & 1.80282 & $\pi *(\mathrm{C} 20-\mathrm{C} 28)$ & 0.32339 & 18.97 & 0.27 & 0.066 \\
\hline $\mathrm{LP}(2) \mathrm{S} 30$ & 1.76003 & $\pi *(\mathrm{C} 20-\mathrm{C} 28)$ & 0.32339 & 17.66 & 0.27 & 0.063 \\
\hline LP(2) S34 & 1.76226 & $\pi^{*}(\mathrm{C} 15-\mathrm{C} 32)$ & 0.32218 & 17.45 & 0.27 & 0.063 \\
\hline$\pi(\mathrm{C} 8-\mathrm{C} 9)$ & 1.80282 & $\pi^{*}(\mathrm{C} 7-\mathrm{C} 10)$ & 0.31685 & 16.92 & 0.29 & 0.065 \\
\hline$\pi(\mathrm{C} 3-\mathrm{C} 4)$ & 1.80546 & $\pi^{*}(\mathrm{C} 1-\mathrm{C} 2)$ & 0.31139 & 16.61 & 0.29 & 0.064 \\
\hline$\pi(\mathrm{C} 1-\mathrm{C} 2)$ & 1.84789 & $\pi *(\mathrm{C} 3-\mathrm{C} 4)$ & 0.36665 & 15.32 & 0.29 & 0.063 \\
\hline$\pi(\mathrm{C} 7-\mathrm{C} 10)$ & 1.85043 & $\pi^{*}(\mathrm{C} 8-\mathrm{C} 9)$ & 0.36906 & 14.95 & 0.29 & 0.063 \\
\hline$\pi(\mathrm{C} 20-\mathrm{C} 28)$ & 1.91327 & $\pi^{*}(\mathrm{C} 8-\mathrm{C} 9)$ & 0.36906 & 11.72 & 0.32 & 0.059 \\
\hline$\pi(\mathrm{C} 15-\mathrm{C} 32)$ & 1.91577 & $\pi *(\mathrm{C} 3-\mathrm{C} 4)$ & 0.36665 & 11.51 & 0.32 & 0.058 \\
\hline
\end{tabular}

Table 9: Second order perturbation theory analysis of Fock matrix on NBO of compound 2

\begin{tabular}{|c|c|c|c|c|c|c|}
\hline Donor(i) & ED/e & Acceptor(j) & ED/e & $\begin{array}{c}\mathrm{E}(2) \\
\text { Kcal/mol }\end{array}$ & $\begin{array}{c}\mathbf{E}(\mathbf{j})-\mathbf{E}(\mathbf{i}) \\
\text { a.u } \\
\end{array}$ & $\begin{array}{c}\text { F(i.j) } \\
\text { a.u }\end{array}$ \\
\hline LP(2) S22 & 1.66342 & $\pi *(\mathrm{C} 1-\mathrm{C} 2)$ & 0.31620 & 21.41 & 0.27 & 0.068 \\
\hline $\mathrm{LP}(2) \mathrm{S} 23$ & 1.67140 & $\pi *(\mathrm{C} 7-\mathrm{C} 10)$ & 0.30949 & 21.10 & 0.28 & 0.068 \\
\hline LP(2) S29 & 1.76658 & $\pi *(\mathrm{C} 13-\mathrm{C} 14)$ & 0.23691 & 20.44 & 0.27 & 0.066 \\
\hline $\mathrm{LP}(2) \mathrm{S} 28$ & 1.77803 & $\pi^{*}(\mathrm{C} 13-\mathrm{C} 14)$ & 0.23691 & 20.40 & 0.27 & 0.067 \\
\hline $\mathrm{LP}(2) \mathrm{S} 22$ & 1.66342 & $\pi^{*}(\mathrm{C} 3-\mathrm{C} 4)$ & 0.36960 & 20.39 & 0.27 & 0.066 \\
\hline $\mathrm{LP}(2) \mathrm{S} 25$ & 1.77979 & $\pi^{*}(\mathrm{C} 16-\mathrm{C} 17)$ & 0.23695 & 20.39 & 0.27 & 0.067 \\
\hline $\mathrm{LP}(2) \mathrm{S} 26$ & 1.77026 & $\pi^{*}(\mathrm{C} 16-\mathrm{C} 17)$ & 0.23695 & 20.37 & 0.27 & 0.066 \\
\hline $\mathrm{LP}(2) \mathrm{S} 23$ & 1.67140 & $\pi^{*}(\mathrm{C} 8-\mathrm{C} 9)$ & 0.36558 & 19.71 & 0.27 & 0.066 \\
\hline $\mathrm{LP}(2) \mathrm{S} 29$ & 1.76658 & $\pi^{*}(\mathrm{C} 15-\mathrm{C} 27)$ & 0.32738 & 19.24 & 0.27 & 0.066 \\
\hline LP(2) S26 & 1.77026 & $\pi^{*}(\mathrm{C} 18-\mathrm{C} 24)$ & 0.32525 & 18.88 & 0.27 & 0.066 \\
\hline $\mathrm{LP}(2) \mathrm{S} 28$ & 1.77803 & $\pi *(\mathrm{C} 15-\mathrm{C} 27)$ & 0.32738 & 17.90 & 0.27 & 0.064 \\
\hline $\mathrm{LP}(2) \mathrm{S} 25$ & 1.77979 & $\pi^{*}(\mathrm{C} 18-\mathrm{C} 24)$ & 0.32525 & 17.60 & 0.28 & 0.064 \\
\hline$\pi(\mathrm{C} 8-\mathrm{C} 9)$ & 1.81785 & $\pi^{*}(\mathrm{C} 18-\mathrm{C} 24)$ & 0.32525 & 17.18 & 0.28 & 0.064 \\
\hline$\pi(\mathrm{C} 3-\mathrm{C} 4)$ & 1.81440 & $\pi *(\mathrm{C} 15-\mathrm{C} 27)$ & 0.32738 & 17.08 & 0.28 & 0.064 \\
\hline$\pi(\mathrm{C} 3-\mathrm{C} 4)$ & 1.81440 & $\pi^{*}(\mathrm{C} 1-\mathrm{C} 2)$ & 0.31620 & 16.77 & 0.29 & 0.064 \\
\hline$\pi(\mathrm{C} 8-\mathrm{C} 9)$ & 1.81785 & $\pi^{*}(\mathrm{C} 7-\mathrm{C} 10)$ & 0.30949 & 16.41 & 0.29 & 0.064 \\
\hline$\pi(\mathrm{C} 7-\mathrm{C} 10)$ & 1.84992 & $\pi^{*}(\mathrm{C} 8-\mathrm{C} 9)$ & 0.36558 & 15.43 & 0.29 & 0.063 \\
\hline$\pi(\mathrm{C} 1-\mathrm{C} 2)$ & 1.85238 & $\pi^{*}(\mathrm{C} 3-\mathrm{C} 4)$ & 0.36960 & 15.05 & 0.29 & 0.063 \\
\hline$\pi(\mathrm{C} 15-\mathrm{C} 27)$ & 1.89677 & $\pi^{*}(\mathrm{C} 3-\mathrm{C} 4)$ & 0.36960 & 11.90 & 0.31 & 0.058 \\
\hline$\pi(\mathrm{C} 18-\mathrm{C} 24)$ & 1.89983 & $\pi^{*}(\mathrm{C} 8-\mathrm{C} 9)$ & 0.36558 & 11.55 & 0.31 & 0.058 \\
\hline
\end{tabular}

The intra molecular interaction for the title compounds is formed by the orbital overlap between: $\pi(\mathrm{C} 3-\mathrm{C} 4)$ and $\pi^{*}(\mathrm{C} 15-\mathrm{C} 32)$ for compound $1, \pi(\mathrm{C} 8-\mathrm{C} 9)$ and $\pi^{*}(\mathrm{C} 18-$ $\mathrm{C} 24)$ for compound $2, \pi(\mathrm{C} 3-\mathrm{C} 4)$ and $\pi^{*}(\mathrm{C} 15-\mathrm{C} 30)$ for compound $\mathbf{3}$ and $\pi(\mathrm{C} 18-\mathrm{C} 22)$ and $\pi^{*}(\mathrm{C} 8-\mathrm{C} 9)$ for compound 4 respectively, which result into intermolecular charge transfer (ICT) causing stabilization of the system. The intra molecular hyper conjugative interactions of $\pi(\mathrm{C} 3-\mathrm{C} 4)$ to $\pi *(\mathrm{C} 15-\mathrm{C} 32)$ for compound $\mathbf{1}, \pi(\mathrm{C} 8-\mathrm{C} 9)$ to $\pi^{*}(\mathrm{C} 18-\mathrm{C} 24)$ for compound $2, \pi(\mathrm{C} 3-\mathrm{C} 4)$ to $\pi^{*}(\mathrm{C} 15-\mathrm{C} 30)$ for compound $\mathbf{3}$ and $\pi(\mathrm{C} 18-\mathrm{C} 22)$ to $\pi^{*}(\mathrm{C} 8-\mathrm{C} 9)$ for compound 4 lead to highest stabilization of $19.23,17.18,19.83$ and $11.87 \mathrm{~kJ}$ $\mathrm{mol}^{-1}$ respectively. In case of $\mathrm{LP}(2) \mathrm{S} 34$ orbital to the $\pi^{*}(\mathrm{C} 13-\mathrm{C} 14)$ for compound $1, \operatorname{LP}(2)$ S22 orbital to $\pi^{*}(\mathrm{C} 1-\mathrm{C} 2)$ for compound $2, \mathrm{LP}(2) \mathrm{S} 39$ orbital to $\pi^{*}(\mathrm{C} 34-\mathrm{C} 35)$ for compound $3, \operatorname{LP}(2)$ S21 orbital to $\pi^{*}(\mathrm{C} 8-\mathrm{C} 9)$ for compound 4 respectively, show the stabilization energy of $22.85,21.41,23.07$ and $21.23 \mathrm{~kJ}$ $\mathrm{mol}^{-1}$ respectively. 
Table 10: Second order perturbation theory analysis of Fock matrix on NBO of compound 3

\begin{tabular}{|c|c|c|c|c|c|c|}
\hline Donor(i) & ED/e & Acceptor $(\mathbf{j})$ & ED/e & $\begin{array}{c}\mathrm{E}(2) \\
\text { Kcal/mol }\end{array}$ & $\begin{array}{c}\mathrm{E}(\mathbf{j})-\mathbf{E}(\mathbf{i}) \\
\text { a.u }\end{array}$ & $\begin{array}{c}F(\mathbf{i} . \mathbf{j}) \\
\text { a.u }\end{array}$ \\
\hline LP(2) S39 & 1.73999 & $\pi^{*}(\mathrm{C} 34-\mathrm{C} 35)$ & 0.22026 & 23.07 & 0.25 & 0.069 \\
\hline LP(2) S32 & 1.75980 & $\pi^{*}(\mathrm{C} 13-\mathrm{C} 14)$ & 0.22068 & 22.76 & 0.25 & 0.068 \\
\hline $\mathrm{LP}(2) \mathrm{S} 28$ & 1.75851 & $\pi^{*}(\mathrm{C} 18-\mathrm{C} 19)$ & 0.21995 & 22.75 & 0.25 & 0.068 \\
\hline LP(2) S33 & 1.75045 & $\pi^{*}(\mathrm{C} 13-\mathrm{C} 14)$ & 0.22068 & 22.37 & 0.25 & 0.068 \\
\hline LP(2) S29 & 1.75001 & $\pi^{*}(\mathrm{C} 18-\mathrm{C} 19)$ & 0.21995 & 22.25 & 0.25 & 0.067 \\
\hline $\mathrm{LP}(2) \mathrm{S} 40$ & 1.74741 & $\pi^{*}(\mathrm{C} 34-\mathrm{C} 35)$ & 0.22026 & 21.92 & 0.26 & 0.067 \\
\hline $\mathrm{LP}(2) \mathrm{S} 25$ & 1.65108 & $\pi^{*}(\mathrm{C} 8-\mathrm{C} 9)$ & 0.37672 & 21.74 & 0.27 & 0.068 \\
\hline $\mathrm{LP}(2) \mathrm{S} 24$ & 1.66989 & $\pi^{*}(\mathrm{C} 3-\mathrm{C} 4)$ & 0.38553 & 20.90 & 0.27 & 0.068 \\
\hline LP(2) S29 & 1.75001 & $\pi^{*}(\mathrm{C} 20-\mathrm{C} 26)$ & 0.32384 & 20.25 & 0.27 & 0.067 \\
\hline LP(2) S33 & 1.75045 & $\pi^{*}(\mathrm{C} 15-\mathrm{C} 30)$ & 0.33086 & 19.99 & 0.27 & 0.067 \\
\hline$\pi(\mathrm{C} 3-\mathrm{C} 4)$ & 1.77776 & $\pi^{*}(\mathrm{C} 15-\mathrm{C} 30)$ & 0.33086 & 19.83 & 0.27 & 0.067 \\
\hline $\mathrm{LP}(2) \mathrm{S} 25$ & 1.65108 & $\pi^{*}(\mathrm{C} 7-\mathrm{C} 10)$ & 0.33037 & 19.82 & 0.27 & 0.065 \\
\hline $\mathrm{LP}(2) \mathrm{S} 24$ & 1.66989 & $\pi^{*}(\mathrm{C} 1-\mathrm{C} 2)$ & 0.38247 & 19.80 & 0.27 & 0.066 \\
\hline $\mathrm{LP}(2) \mathrm{S} 40$ & 1.74741 & $\pi^{*}(\mathrm{C} 23-\mathrm{C} 36)$ & 0.35872 & 19.63 & 0.27 & 0.067 \\
\hline LP(2) S39 & 1.73999 & $\pi^{*}(\mathrm{C} 23-\mathrm{C} 36)$ & 0.35872 & 19.44 & 0.27 & 0.066 \\
\hline$\pi(\mathrm{C} 8-\mathrm{C} 9)$ & 1.78802 & $\pi *(\mathrm{C} 20-\mathrm{C} 26)$ & 0.32384 & 19.17 & 0.27 & 0.066 \\
\hline$\pi(\mathrm{C} 8-\mathrm{C} 9)$ & 1.78802 & $\pi^{*}(\mathrm{C} 7-\mathrm{C} 10)$ & 0.33037 & 18.29 & 0.29 & 0.067 \\
\hline $\mathrm{LP}(2) \mathrm{S} 28$ & 1.75851 & $\pi *(\mathrm{C} 20-\mathrm{C} 26)$ & 0.32384 & 17.73 & 0.27 & 0.063 \\
\hline LP(2) S32 & 1.75980 & $\pi^{*}(\mathrm{C} 15-\mathrm{C} 30)$ & 0.33086 & 17.46 & 0.27 & 0.063 \\
\hline$\pi(\mathrm{C} 3-\mathrm{C} 4)$ & 1.77776 & $\pi^{*}(\mathrm{C} 1-\mathrm{C} 2)$ & 0.38247 & 17.20 & 0.28 & 0.065 \\
\hline
\end{tabular}

Table 11: Second order perturbation theory analysis of Fock matrix on NBO of compound 4

\begin{tabular}{|c|c|c|c|c|c|c|}
\hline Donor(i) & ED/e & Acceptor(j) & ED/e & $\begin{array}{c}\mathrm{E}(2) \\
\text { Kcal/mol } \\
\end{array}$ & $\begin{array}{c}\mathbf{E}(\mathbf{j})-\mathbf{E}(\mathbf{i}) \\
\text { a.u }\end{array}$ & $\begin{array}{c}F(\mathbf{i} . \mathbf{j}) \\
\text { a.u }\end{array}$ \\
\hline $\mathrm{LP}(2) \mathrm{S} 21$ & 1.65040 & $\pi^{*}(\mathrm{C} 8-\mathrm{C} 9)$ & 0.37846 & 21.23 & 0.27 & 0.067 \\
\hline LP(2) S56 & 1.75601 & $\pi^{*}(\mathrm{C} 53-\mathrm{C} 54)$ & 0.23801 & 21.13 & 0.27 & 0.067 \\
\hline LP(2) S27 & 1.76480 & $\pi^{*}(\mathrm{C} 13-\mathrm{C} 14)$ & 0.23753 & 20.62 & 0.27 & 0.066 \\
\hline $\mathrm{LP}(2) \mathrm{S} 24$ & 1.76488 & $\pi^{*}(\mathrm{C} 16-\mathrm{C} 17)$ & 0.23737 & 20.53 & 0.27 & 0.066 \\
\hline LP(2) S20 & 1.66868 & $\pi^{*}(\mathrm{C} 3-\mathrm{C} 4)$ & 0.38460 & 20.41 & 0.27 & 0.067 \\
\hline LP(2) S23 & 1.77809 & $\pi^{*}(\mathrm{C} 16-\mathrm{C} 17)$ & 0.23737 & 20.41 & 0.27 & 0.067 \\
\hline $\mathrm{LP}(2) \mathrm{S} 26$ & 1.77806 & $\pi^{*}(\mathrm{C} 13-\mathrm{C} 14)$ & 0.23753 & 20.34 & 0.27 & 0.067 \\
\hline LP(2) S55 & 1.76189 & $\pi *(\mathrm{C} 53-\mathrm{C} 54)$ & 0.23801 & 20.20 & 0.27 & 0.066 \\
\hline LP(2) S55 & 1.76189 & $\pi^{*}(\mathrm{C} 19-\mathrm{C} 52)$ & 0.35390 & 20.06 & 0.27 & 0.067 \\
\hline LP(2) S20 & 1.66868 & $\pi^{*}(\mathrm{C} 1-\mathrm{C} 2)$ & 0.37698 & 20.03 & 0.27 & 0.066 \\
\hline LP(2) S21 & 1.65040 & $\pi *(\mathrm{C} 7-\mathrm{C} 10)$ & 0.32854 & 19.97 & 0.27 & 0.066 \\
\hline LP(2) S56 & 1.75601 & $\pi *(\mathrm{C} 19-\mathrm{C} 52)$ & 0.35390 & 19.90 & 0.26 & 0.067 \\
\hline $\mathrm{LP}(2) \mathrm{S} 24$ & 1.76488 & $\pi^{*}(\mathrm{C} 18-\mathrm{C} 22)$ & 0.32765 & 19.28 & 0.27 & 0.066 \\
\hline $\mathrm{LP}(2) \mathrm{S} 27$ & 1.76480 & $\pi^{*}(\mathrm{C} 15-\mathrm{C} 25)$ & 0.33286 & 19.02 & 0.27 & 0.066 \\
\hline LP(2) S23 & 1.77809 & $\pi^{*}(\mathrm{C} 18-\mathrm{C} 22)$ & 0.32765 & 17.92 & 0.27 & 0.064 \\
\hline $\mathrm{LP}(2) \mathrm{S} 26$ & 1.77806 & $\pi^{*}(\mathrm{C} 15-\mathrm{C} 25)$ & 0.33286 & 17.54 & 0.28 & 0.064 \\
\hline$\pi(\mathrm{C} 18-\mathrm{C} 22)$ & 1.89540 & $\pi^{*}(\mathrm{C} 8-\mathrm{C} 9)$ & 0.37846 & 11.87 & 0.31 & 0.059 \\
\hline$\pi(\mathrm{C} 19-\mathrm{C} 52)$ & 1.89205 & $\pi^{*}(\mathrm{C} 1-\mathrm{C} 2)$ & 0.37698 & 9.89 & 0.32 & 0.054 \\
\hline$\sigma(\mathrm{C} 25-\mathrm{C} 44)$ & 1.96695 & $\sigma^{*}(\mathrm{C} 15-\mathrm{S} 27)$ & 0.03776 & 5.73 & 0.78 & 0.060 \\
\hline$\sigma(\mathrm{C} 22-\mathrm{C} 48)$ & 1.96686 & $\sigma^{*}(\mathrm{C} 18-\mathrm{S} 24)$ & 0.03792 & 5.71 & 0.78 & 0.060 \\
\hline
\end{tabular}

\subsection{Nonlinear Optical Properties (NLO)}

NLO techniques are considered as one among the most structure sensitive method to study molecular structure and assemblies since the potential or organic materials for NLO device have been proven. Organic molecules able to manipulate photonic signals efficiently are of importance in technologies such as optical communication, optical computing, and dynamic image processing $^{36}$. DFT has been extensively used as an effective method to investigate NLO properties of organic materials. In order to gain insight into NLO property of title compound, the first static hyperpolarizability $(\beta)$ were calculated by the finite field perturbation method in vacuum as well as incorporating the solvent factors with increasing polarity. First hyperpolarizability is a third rank tensor that can be described by a $3 \times 3 \times 3$ matrix. The 27 components of the $3 \mathrm{D}$-matrix can be reduced to 10 components due to the Kleinman symmetry ${ }^{37}$. The components of $\beta$ are defined as the coefficients in the Taylor series expansion of the energy in the external electric field. When the external electric field is weak and homogeneous this expansion becomes:

$$
E=E^{0}-\mu_{i} F_{i}-1 / 2 \alpha_{i j} F_{i} F_{j}-1 / 6 \beta_{i j k} F_{i} F_{j} F_{k}+1 / 24 \gamma_{i j k l}
$$


where $\mathrm{E}^{0}$ is the energy of the unperturbed molecules, $\mathrm{F}_{\mathrm{i}}$ the field at the origin and $\mu_{\mathrm{i}}, \alpha_{\mathrm{ij}}, \beta_{\mathrm{ijk}}$ and $\gamma_{\mathrm{ijkl}}$ are the components of dipole moment, polarizability, and the first hyperpolarizability respectively. Using the $\mathrm{x}$, $\mathrm{y}$ and $z$ components of $\beta$ obtained from Gaussian 09 output, the magnitude of the mean first hyperpolarizability tensor can be calculated.

The total static dipole moment is $\mu_{t o t}=\left(\mu_{x}^{2}+\mu_{y}^{2}+\mu_{z}^{2}\right)^{1 / 2}$

The mean polarizability is $\alpha_{0}=\left(\alpha_{x x}+\alpha_{y y}+\alpha_{z z}\right) / 3$

The anisotropy polarizability is

$\Delta \alpha=2^{-1 / 2}\left[\left(\alpha_{x x}-\alpha_{y y}\right)^{2}+\left(\alpha_{y y}-\alpha_{z z}\right)^{2}+\left(\alpha_{z z}-\alpha_{x x}\right)^{2}+6 \alpha^{2} x z\right]^{1 / 2}$ and the mean first hyperpolarizability is $\beta_{0}=\left(\beta_{x}^{2}+\beta_{y}^{2}+\beta_{z}^{2}\right)^{1 / 2}$

and

$$
\begin{aligned}
& \beta_{x}=\left(\beta_{x x x}+\beta_{x y y}+\beta_{x z z}\right) \\
& \beta_{y}=\left(\beta_{y y y}+\beta_{y z z}+\beta_{y x x}\right) \\
& \beta_{z}=\left(\beta_{z z z}+\beta_{z x x}+\beta_{z y y}\right)
\end{aligned}
$$

The first static hyperpolarizability $\left(\beta_{0}\right)$ and its related properties of title compounds have been computed using B3LYP/6-31G $(\mathrm{d}, \mathrm{p})$ level based on finite field approach and shown in Table 12 .

\begin{tabular}{|c|c|c|c|c|}
\hline Parameters & Compound 1 & Compound 2 & Compound 3 & Compound 4 \\
\hline$\beta_{x x x}$ & -121.5512 & -150.1263 & 5.0493 & -3.0010 \\
\hline$\beta_{y y y}$ & -19.5719 & 37.1972 & 18.3092 & 24.5356 \\
\hline $\boldsymbol{\beta}_{z z z}$ & -2.5386 & -1.0018 & 1.3466 & -3.9574 \\
\hline$\beta_{x y y}$ & 84.3712 & 95.7305 & 34.7951 & 80.9100 \\
\hline$\beta_{x x y}$ & -162.6516 & 189.3376 & -102.0284 & -85.5066 \\
\hline $\boldsymbol{\beta}_{x x z}$ & -54.4601 & -53.0192 & -64.0034 & -80.8182 \\
\hline $\boldsymbol{\beta}_{x z z}$ & -45.8577 & -55.8834 & 56.4871 & 54.2933 \\
\hline $\boldsymbol{\beta}_{y z z}$ & -3.3246 & 5.5184 & -20.5327 & -36.1668 \\
\hline$\beta_{y y z}$ & -8.3396 & -8.4140 & -67.0276 & -78.0401 \\
\hline $\boldsymbol{\beta}_{x y z}$ & 16.5318 & 9.4698 & 20.8458 & 25.4880 \\
\hline$\beta_{0}($ esu $) \times 10^{-33}$ & 247.9135 & 310.4428 & 185.6699 & 204.5481 \\
\hline$\mu_{x}$ & -0.0649 & -0.3470 & 1.5926 & 2.0672 \\
\hline $\boldsymbol{\mu}_{y}$ & -1.2689 & 2.3490 & -1.1695 & -1.7797 \\
\hline $\boldsymbol{\mu}_{z}$ & -0.3978 & -0.4539 & -1.0008 & -1.6486 \\
\hline$\mu_{t o t}(\mathrm{D})$ & 1.3313 & 2.4175 & 2.2149 & 3.1873 \\
\hline$\alpha_{x x}$ & -137.2983 & -168.2622 & -192.9694 & -235.6603 \\
\hline$\alpha_{y y}$ & -161.0968 & -195.0899 & -174.4119 & -218.5017 \\
\hline$\alpha_{z z}$ & -171.5538 & -208.6007 & -211.9540 & -260.3748 \\
\hline$\alpha_{x y}$ & -2.8168 & 1.7521 & 3.5466 & 11.4015 \\
\hline$\alpha_{x z}$ & 8.8212 & 10.4312 & -6.9355 & -9.0632 \\
\hline$\alpha_{y z}$ & 2.4475 & -2.5874 & -0.1302 & 0.9577 \\
\hline$\alpha(\mathrm{esu}) \times 10^{-24}$ & 34.6380 & 40.2549 & 35.2022 & 44.3672 \\
\hline$\Delta \alpha(\mathrm{esu}) \times 10^{-24}$ & 5.1334 & 5.9658 & 5.2170 & 6.5752 \\
\hline
\end{tabular}

Table 12: The dipole moments $\mu_{\text {tot }}$ (D), polarizability $\alpha_{0}$ (esu), the anisotropy of the polarizability $\Delta \alpha$ (esu) and the first hyperpolarizability $\beta_{0}$ (esu) of bis and tris (1,3-dithiole) TTF 1-4.

Since the values of the polarizabilities $(\Delta \alpha)$ and the hyperpolarizabilities $\left(\beta_{0}\right)$ of the GAUSSIAN 09 output are obtained in atomic units (a.u.), the calculated values have been converted into electrostatic units (e.s.u.) (for $\alpha ; 1$ a.u $=0.1482 \times 10^{-24}$ e.s.u., for $\beta ; 1$ a.u $=8.6393 \mathrm{x}$ $10^{-33}$ e.s.u.). The calculated values of dipole moment $\left(\mu_{\text {tot }}\right)$ for the title compounds were found to be 1.3313, $2.4175,2.2149$ and $3.1873 \mathrm{D}$ respectively, which are approximately three times than to the value for urea $(\mu=$ 1.3732 D). Urea is one of the prototypical molecules used in the study of the NLO properties of molecular systems. Therefore, it has been used frequently as a threshold value for comparative purposes. The calculated values of polarizability are $34.6380 \times 10^{-24}$, $40.2549 \times 10^{-24}, 35.2022 \times 10^{-24}$ and $44.3672 \times 10^{-24}$ esu respectively; the values of anisotropy of the polarizability are 5.1334, 5.9658, 5.2170 and 6.5752 esu, respectively. The magnitude of the molecular hyperpolarizability $\left(\beta_{0}\right)$ is one of important key factors in a NLO system. The DFT/6-31G (d,p) calculated first hyperpolarizability value $\left(\beta_{0}\right)$ of bis and tris $(1,3-$ dithiole) TTF molecules are equal to $247.9135 \times 10^{-33}$, $310.4428 \times 10^{-33}, 185.6699 \times 10^{-33}$ and $204.5481 \times 10^{-33}$ esu. The first hyperpolarizability of title molecules is approximately $0.72,0.90,0.54$ and 0.60 times than those of urea ( $\beta$ of urea is $343.272 \times 10^{-33}$ esu obtained by B3LYP/6-311G (d,p) method). The above results show that bis and tris (1,3-dithiole) TTF 1-4 might have not the NLO proprieties.

\section{CONCLUSION}

In this investigation we reported a detailed theoretical study of bis and tris (1,3-dithiole) TTF $\mathbf{1 - 4}$ at DFT/B3LYP method with 6-31G (d,p) basis set. Molecular parameters such as bond length, bond angle and dihedral angle were calculated with the same method. MEP predicts the most reactive part in the molecules. The difference in HOMO and LUMO energy supports the charge transfer interaction within the molecule. The chemical reactivity and site selectivity of 
the molecules have been determined with the help of global and local reactivity descriptors. The stabilization energies have been calculated from second order perturbation theory. The predicted NLO properties of title compounds are much smaller than those of urea which indicates that have not the NLO materials.

\section{REFERENCES}

1. Brillante A, Bilotti I, Della Valle RG, Venuti E, Milita S, Dionigi $\mathrm{C}$ et al, The Four Polymorphic Modifications of the Semiconductor Dibenzo-Tetrathiafulvalene. Cryst Eng Comm, 2008; 10(12):1899-1909. http://dx.doi.org/10.1039/B810993A.

2. Crivillers N, Mas-Torrent M, Bromley ST, Wurst K, Veciana $\mathrm{J}$, Rovira C, Influence of Intermolecular Interactions on the Formation of tetra(carbomethoxy)-tetrathiafulvalene Assemblies. Chem Phys Chem, 2007; 8(10):1565-1571. http://dx.doi.org/10.1002/cphc.200700198.

3. Crivillers N, Oxtoby NS, Mas-Torrent M, Veciana J, Rovira $\mathrm{C}$, Improved Synthesis of the High-Mobility Organic Semiconductor Dithio-phene-Tetrathiafulvalene. Synthesis, 2007; 11:1621-1623. http://dx.doi.org/10.1055/s-2007966053.

4. Leufgen M, Rost O, Gould C, Schmidt G, Geurts J, Molenkamp LW, et al, High-mobility Tetrathiafulvalene Organic Field-Effect Transistors from Solution Processing, Org Electron, 2008, 9(6), 1101-1106. http://dx.doi.org/10.1016/j.orgel.2008.08.011.

5. Rosokha SV, Kochi JK. Molecular and Electronic Structures of the Long-Bonded $\pi$-Dimers of Tetrathiafulvalene CationRadical in Intermolecular Electron Transfer and in (SolidState) Conductivity, J Am Chem Soc, 2007; 129(4):828-838. http://dx.doi.org/10.1021/ja064166x.

6. Fourmigue M, Batail P, Activation of Hydrogen- and Halogen-Bonding Interactions in Tetrathiafulvalene-Based Crystalline Molecular Conductors, Chem Rev, 2004; 104(11):5379-5418. http://dx.doi.org/10.1021/cr030645s.

7. Day P, Kurmoo M, Molecular Magnetic Semiconductors, Metals and Superconductors: BEDT-TTF Salts with Magnetic Anions, J Mater Chem, 1997; 7(8):1291-1295. http://dx.doi.org/10.1039/A608508C.

8. Bryce MR, Recent Progress on Conducting Organic ChargeTransfer Salts, Chem Soc Rev, 1991; 20(3):355-390. http://dx.doi.org/10.1039/CS9912000355.

9. Moore AJ, Goldenberg LM, Bryce MR, Petty MC, Monkman AP, Morenco C, et al, Cation Recognition by Self- Assembled Layers of Novel Crown- Annelated Tetrathiafulvalenes, Adv Mater, 1998; 10(5):395-398 http://dx.doi.org/10.1002/(SICI)15214095(199803)10:5<395::AID-ADMA395>3.0.CO;2-I.

10. Segura JL, Martín N, New Concepts in Tetrathiafulvalene Chemistry, Angew Chem Int Ed, 2001; 40(8):1372-1409. http://dx.doi.org/10.1002/15213773(20010417)40:8<1372::AID-ANIE1372>3.0.CO;2-I

11. Mas-Torrent M, Durkut M, Hadley P, Ribas X, Rovira C. High Mobility of Dithiophene-Tetrathiafulvalene SingleCrystal Organic Field Effect Transistors, J Am Chem Soc, 2004; 126(4):984-985. http://dx.doi.org/10.1021/ja0393933.

12. U Soykan, S Cetin, B Ozturk, F Karaboga, Y Zalaoglu, M Dogruer, et al, Synthesis and Characterization of pbenzophenoneoxycarbonylphenyl Acrylate by Means of Experimental Measurements and Theoretical Approaches, and Bulk Melt Polymerization, J Mol Struct, 2013; 1049:479487. http://dx.doi.org/10.1016/j.molstruc.2013.07.003.

13. Breda S, Reva I, Fausto R, Molecular Structure and Vibrational Spectra of 2(5H)-Furanone and 2(5H)thiophenone Isolated in Low Temperature Inert Matrix, J Mol Struct, 2008; 887(1-3):75-86. http://dx.doi.org/10.1016/j.molstruc.2008.02.034.

14. Foresman JB, Frisch A, Exploring Chemistry with Electronic Structure Methods: a Guide to Using Gaussian, second ed., Gaussian, Pittsburgh; 1996.

\section{Acknowledgments}

This work was generously supported by the (General Directorate for Scientific Research and Technological Development, DGRS-DT) and Algerian Ministry of Scientific Research.

15. Rauhut G, Pulay P, Transferable Scaling Factors for Density Functional Derived Vibrational Force Fields, J Phys Chem, 1995; 99(10):3093-3100.

http://dx.doi.org/10.1021/j100010a019.

16. Scott AP, Radom L, Harmonic Vibrational Frequencies: An Evaluation of Hartree-Fock, Møller-Plesset, Quadratic Configuration Interaction, Density Functional Theory, and Semiempirical Scale Factors, J Phys Chem, 1996; 100(41) 16502-16513. http://dx.doi.org/10.1021/jp960976r.

17. Durig JR, Ganguly A, El-Defrawy AM, Guirgis GA, Gounev TK, Herrebout WA, Conformational Stability from VariableTemperature Infrared Spectra of Xenon Solutions, $\mathrm{r}_{0}$ Structural Parameters, and Vibrational Assignment of Pyrrolidine, J Phys Chem A, 2011; 115(26):7473-7483. http://dx.doi.org/10.1021/ip200692t.

18. Bałczewski P, Kudelska W, Bodzioch A, Comprehensive Heterocyclic Chemistry III, 1st Edition, Volume Set; 2008 , 15, 12500. ISBN: 9780080449920

19. Frisch MJ, Trucks GW, Schlegel HB, Scuseria GE, Robb MA, Cheeseman JR, et al, Gaussian 09, Revision C.01; Gaussian Inc.: Wallingford, CT, USA; 2010.

20. Fukui K, Yonezawa T, Shingu HJ, A Molecular Orbital Theory of Reactivity in Aromatic Hydrocarbons, J Chem Phys, 1952; 20(4):722-725.

http://dx.doi.org/10.1063/1.1700523.

21. Padmaja L, Ravikumar C, Sajan D, Joe IH, Jayakumar VS, Pettit GR, Neilsen FO, Density Functional Study on the Structural Conformations and Intramolecular Charge Transfer from the Vibrational Spectra of the Anticancer Drug Combretastatin- A2. J. Raman Spectrosc, 2009; 40(4):419428. http://dx.doi.org/10.1002/jrs.2145.

22. Ravikumar C, Joe IH, Jayakumar VS, Charge Transfer Interactions and Nonlinear Optical Properties of Push-Pull Chromophore Benzaldehyde Phenylhydrazone: A Vibrational Approach. Chem. Phys. Lett, 2008; 460(4-6):552-558. http://dx.doi.org/10.1016/j.cplett.2008.06.047.

23. Pearson RG, Absolute Electronegativity and Hardness: Applications to Organic Chemistry. J. Org. Chem, 1989; 54(6):1430-1432. http://dx.doi.org/10.1021/jo00267a034.

24. Parr RG, Pearson RG, Absolute Hardness: Companion Parameter to Absolute Electronegativity. J. Am. Chem. Soc, 1983; 105(26):7512-7516. http://dx.doi.org/10.1021/ja00364a005.

25. Geerlings P, De Proft F, Langenaeker W, Conceptual Density Functional Theory. Chem. Rev, 2003; 103(5):1793-1873. http://dx.doi.org/10.1021/cr990029p.

26. Parr RG, Szentpaly L, Liu S, Electrophilicity Index. J. Am. Chem. Soc, 1999; 121(9):1922-1924. http://dx.doi.org/10.1021/ja983494x.

27. Chattaraj K, Giri S, Aromaticity in Polyacene Analogues of Inorganic Ring Compounds. J. Phys. Chem. A, 2007; 111(21):11116-11121. http://dx.doi.org/10.1021/jp071030s.

28. Parr RG, Yang W, Density-functional Theory of Atoms and Molecules, Oxford University Press, New York, 1989.

29. Parr RG, Yang W, Density Functional Approach to the Frontier-Electron Theory of Chemical Reactivity. J. Am. Chem. Soc, 1984; 106(14):4049-4050. http://dx.doi.org/10.1021/ja00326a036.

30. Yang W, Mortier WJ, The Use of Global and Local Molecular Parameters for the Analysis of the Gas-Phase Basicity of Amines. J. Am. Chem. Soc, 1986; 108(19);57085711. http://dx.doi.org/10.1021/ja00279a008.

31. James C, Amal Raj A, Reghunathan R, Joe IH, Jayakumar VS, Structural Conformation and Vibrational Spectroscopic 
Studies of 2,6- bis (p- N,N- dimethyl benzylidene) cyclohexanone Using Density Functional Theory. J. Raman Spectrosc, 2006; 37(12);1381-1392.

http://dx.doi.org/10.1002/jrs.1554.

32. Liu J, Chen ZR, Yuan SF, Study on the Prediction of Visible Absorption Maxima of Azobenzene Compounds. J. Zhejing Univ. Sci. B, 2005; 6(6):584-589. PMC1389895

33. Foster JP, Weinhold F, Natural Hybrid Orbitals. J. Am. Chem. Soc, 1980; 102(24):7211-7218. http://dx.doi.org/10.1021/ja00544a007.

34. Reed AE, Curtiss LA, Weinhold F, Intermolecular Interactions from a Natural Bond Orbital, Donor-Acceptor
Viewpoint. Chem. Rev, 1988; 88(6):889-926. http://dx.doi.org/10.1021/cr00088a005.

35. Liu CG, Guan XH, Redox and photoisomerization switching of the second-order optical nonlinearity of a tetrathiafulvalene derivative of spiropyran across five states: A DFT study. Physical Chemistry Chemical Physics, 2012; 14(15);5297-5306. http://dx.doi.org/10.1039/c2cp23293f.

36. Kolinsky PV, New Materials and their Characterization for Photonic Device Applications. Opt. Eng, 1992; 31(8):11676 11684. http://dx.doi.org/10.1117/12.58844.

37. Kleinmann DA, Nonlinear Dielectric Polarization in Optical Media. Phys. Rev, 1962; 126(6):1977. http://dx.doi.org/10.1103/PhysRev.126.1977. 